\title{
Association Between Blood Urea Nitrogen to Creatinine Ratio and in-hospital Mortality Among Patients With Acute Myocardial Infarction- A Retrospective Cohort Study
}

Sulan Huang ( $\square$ huangsulanjiayou3@126.com )

The First People's Hospital of Changde

Ning Guo

The First People's Hospital of Changde

\section{Xiangjie Duan}

The First People's Hospital of Changde

Quan Zhou

The First People's Hospital of Changde

Zhixiang Zhang

The First People's Hospital of Changde

Li Luo

The First People's Hospital of Changde

\section{Liangqing $\mathrm{Ge}$}

The First People's Hospital of Changde

\section{Research Article}

Keywords: elCU Collaborative Research Database, Intensive care unit, BUN/Cr ratio, In-hospital mortality

Posted Date: February 9th, 2022

DOl: https://doi.org/10.21203/rs.3.rs-1286247/v1

License: (영 This work is licensed under a Creative Commons Attribution 4.0 International License. Read Full License 


\section{Abstract}

Purpose: This study aimed to determine the association between blood urea nitrogen (BUN) and creatinine(Cr) ratio and in-hospital mortality in patients with acute myocardial infarction(AMI).

Patients and Methods: This retrospective cohort study included adult patients ( $\geq 18$ years of age) who were admitted to the intensive care unit (ICU) with a primary diagnosis of AMI were enrolled. Their data were collected from the eICU Collaborative Research Database (eICU-CRD) throughout the continental USA. The data collected from the database included demographic data, vital signs, laboratory test data, and comorbidities. The clinical endpoint was in-hospital mortality. The Cox proportional hazards model was used to evaluate the prognostic values of the basic BUN/Cr ratio, and the Kaplan-Meier method was used to plot survival curves. Subgroup analyses were performed to measure mortality across various subgroups.

Results: In total, 3,831 eligible patients were included. In the multivariate analysis, after being adjusted for age, sex, and ethnicity, the BUN/Cr ratio was found to be a significant risk predictor of in-hospital mortality. The nonlinear relationship between the BUN/Cr ratio and in-hospital mortality was explored in a dosedependent manner with an apparent inflection point of 18. Furthermore, after adjusting for more confounding factors, the BUN/Cr ratio remained a significant predictor of in-hospital mortality (tertile 3 vs.tertile 1: hazard ratio 2.14; $95 \%$ confidence interval 1.16-3.97; $p<0.05$ ). The Kaplan-Meier curve for tertiles of the BUN/Cr ratio indicated that survival rates were highest and lowest when the BUN/Cr ratio was $\leq 15.12$ and $\geq 19.41$, respectively, after adjustment for age, sex, and ethnicity $(\mathrm{p}<0.001)$.

Conclusion: Our findings showed that a higher BUN/Cr ratio was associated with an increased risk of inhospital mortality in patients with AMI. These results support a revision of how we predict the prognosis of patients with AMI.

\section{Background}

Acute myocardial infarction (AMI) is a fatal disease that results in high morbidity and mortality rates. Blood urea nitrogen (BUN) and creatinine ( $\mathrm{Cr}$ ) are the end products of nitrogen metabolism in humans. They are small molecules that can be filtered from nephrons. Usually, approximately $30-40 \%$ of BUN is reabsorbed from the kidney tubules. In contrast, $\mathrm{Cr}$ is not as well reabsorbed as BUN[1,2]. BUN is an important parameter that reflects the relationship between the patient's kidney condition, protein metabolism level, and nutritional status. Studies showed that urea nitrogen levels are closely related to mortality [3,4]. A high BUN level could be a useful predictor of in-hospital mortality in patients with AMI [5]. Clinically, Cr content is often used to detect changes in renal function, which aids in the detection of renal failure or improvement in renal function. This finding was augmented by that of Granger et al. [6]who reported that $\mathrm{Cr}$ was a marker of renal function, and the relationship between renal dysfunction and increased mortality was well established in patients with AMI.

The BUN/Cr ratio is defined as the ratio of BUN to serum $\mathrm{Cr}$. As a new biomarker, the BUN/Cr ratio has emerged as an independent prognostic indicator of poor outcomes in different disease conditions, such as acute and chronic heart failure [7-9], acute and chronic kidney injury [10], and ischemic stroke [11]. Studies 
demonstrated that an elevated BUN/Cr ratio was associated with poor prognosis in patients with acute heart failure(AHF). Moreover, an elevated BUN/Cr ratio was found to be an independent predictor of allcause mortality $[1,12]$.

There is existing research on the risk factors for mortality in patients with heart failure. However, the relationship between BUN/Cr ratio and in-hospital mortality has not been fully investigated in patients with $\mathrm{AMI}$ in the intensive care unit(ICU). In our study, we aimed to comprehensively evaluate the role of the $\mathrm{BUN} / \mathrm{Cr}$ ratio in predicting the severity and survival of patients with AMI.

\section{Material And Methods}

\section{Study design}

This was a multicenter retrospective observational study. Analyses were carried out on data subsets obtained from participants in the electronic intensive care unit Collaborative Research Database (elCU-CRD), which was an open-access de-identified dataset of patients maintained by the Laboratory for Computational Physiology at the Massachusetts Institute of Technology. The ICU-CRD covered patients at 208 US hospitals that were monitored by the elCU programs between 2014 and 2015 [13,14]. The database includes records of demographics, hourly physiologic readings from bedside monitors, disease diagnoses via the International Classification of Diseases, Ninth Revision codes, and other clinical data collected during routine medical care. Since all protected health information was de-identified, the requirement for individual patient consent was waived. The use of this database was approved by the institutional review boards of Massachusetts Institute of Technology (Cambridge,MA, USA). All authors of this manuscript completed the necessary training and received permission to access the database. One author (Xiangjie Duan) obtained access to the database and was responsible for data extraction (certification number:42039823).Bona fide researchers can apply to access the Collaborative Research Database via a standard application procedure (further details available at: https://eicu-crd.mit.edu/about/eicu/).

\section{Clinical endpoints}

The primary endpoint of this study was in-hospital mortality. The patients were divided into two groups: survivors and non-survivors. The intergroup differences in parameters measured in the ICU were then evaluated.

\section{Study Population}

Patients were diagnosed with AMI according to the International Classification of Diseases 9 code (ICD-9), which was 140 .This study enrolled adult patients( $\geq 18$ years) admitted to the ICU. Only patients at the first admission with a first diagnosis of AMI were included. Patients were excluded if the date of death was less than the date of ICU hospitalization to avoid potential typographical errors in the original data. Patients without BUN and $\mathrm{Cr}$ measurements during ICU admission were also excluded from the study. Patients with 
an eGRF $₫ 60 \mathrm{~mL} / \mathrm{min} /$ per $1.73 \mathrm{~m}^{2}$ were also excluded. The study population was comprised of 3,831 patients with AMI. The selection procedure for the study participants is summarized in Fig.1.

\section{Definition of AMI}

Clinical evidence of acute myocardial injury was defined as a rise and/or fall in the cardiac troponin (or cTn) values with at least one value $>99$ th percentile of the upper reference limit and at least one of the following symptoms of myocardial ischemia: symptoms of acute myocardial ischemia, new ischemic electrocardiogram (ECG) changes, development of pathological Q waves, and imaging evidence of new loss of viable myocardium or new regional wall motion abnormality in a pattern consistent with an ischemic etiology $[15,16]$.

\section{Statistical analyses}

Categorical variables are expressed as counts and percentages in each category. Continuous variables are specified as appropriate means and standard deviations or medians and interquartile ranges. The Student's $t$-test and Mann-Whitney $U$ test were used for continuous variables. The $\chi^{2}$ and Fisher's exact tests were used for categorical variables. First, we used multivariate models with crude and adjusted hazard ratios (HRs). We used the generalized additive model (GAM) to adjust the continuous variables in Model II. The covariates that were significantly associated with the response variable $(p<0.05)$ or those that changed the effect estimate by $10 \%$ or more were retained in the final adjusted model [17]. We then used the GAM to identify the nonlinear relationship between BUN/Cr ratio and in-hospital mortality. If a nonlinear correlation was detected, a two-piecewise linear regression model was used to determine the threshold effect of the BUN/Cr ratio on in-hospital mortality in accordance with the smoothing plot. If the BUN/Cr and in-hospital mortality ratio appeared in the smoothing plot, the inflection point was determined automatically by the recursive method using the maximum model likelihood [18-19].Finally, we inspected the modification and interaction of the subgroups using the likelihood ratio test. We generated receiver operating characteristic (ROC) curves to measure the sensitivity and specificity of the BUN/Cr ratio and calculated the area under the curve (AUC) to ascertain the quality of the BUN/Cr ratio as a predictor of in-hospital mortality in patients with AMI. Moreover, we determined the relationship between BUN/Cr ratio and the classic scoring systems (APACHE scores).

All data were analyzed using R software (version 3.42) and Empower Stats version 2.17.8 (http://www.empowerstats.com/cn/). Statistical significance was defined as a p-value of less than 0.05 , and all reported $p$-values were two-sided.

\section{Results}

\section{Study participants and baseline characteristics}


The data of a total of 6,616 AMI patients were extracted from the database. Patients without data for BUN $(n=328)$ or $\mathrm{Cr}(\mathrm{n}=50)$ levels were excluded from the study. Patients with an eGRF $₫ 60 \mathrm{~mL} / \mathrm{min} /$ per 1.73 $\mathrm{m}^{2}$ were excluded. A total of $3,831(57.9 \%)$ patients were included in the statistical analyses. The ICU admission rate of patients without a BUN or Cr level was $5.7 \%$ (378 out of 6,616 patients), and the overall inhospital mortality rate was $3.71 \%$ (142 out of 3,831 patients). The mean $\mathrm{BUN} / \mathrm{Cr}$ ratio was $18.6 \pm 8.2$. A flow chart of the study is shown in Fig.1.

The baseline data of the study population are given in Table1. According to the BUN/Cr ratio, 1271, 1274, and 1286 patients fell into the first $(<14.6)$, second $(\geq 14.7$ and $<19.8)$, and third $(\geq 20.0)$ tertiles, respectively. In general, the patients' mean age was $62.2 \pm 12.4$ years, and 2,689(70.2\%) patients were male patients. No statistically significant differences were detected between the groups in terms of the levels of aspartate aminotransferase (AST), alanine aminotransferase (ALT), international normalized ratio (INR), heart rate, systolic blood pressure (SBP), diastolic blood pressure (DBP), capillary blood glucose (CABG), and incidence of percutaneous coronary intervention $(\mathrm{PCl})$ between the different groups (all $p$ values $>0.05$ ). Factors observed among participants with high BUN/Cr ratio levels included having an older age, being a Caucasian, having a longer hospital stay, and having higher WBC, RDW, HDL, and potassium values(all $p$ values $<0.05)$. The opposite was observed for body mass index (BMI), red blood cell (RBC) count, levels of platelets, (total cholesterol)TC, triglycerides (TG), and low-density lipoprotein (LDL), heart rate (HR), and history of diabetes and hypertension (all $p$ values $<0.05$ ).

We illustrated the in-hospital mortality of the two groups in supplementary Fig.1.The mortality rate of nonSTEMI patients was $4.9 \%$, which was significantly higher than that of the STEMI group $(2.8 \%, p=0.001)$.

\section{Kaplan-Meier Survival Curves of the BUN/Cr Ratio for Predicting the In-Hospital Mortality Among Patients with AMI}

The Kaplan-Meier curve for the tertiles of the BUN/Cr ratio is shown in Fig.2. The figure indicated that survival rates were highest when the BUN/Cr ratio was $\leq 15.12$ and lowest when the BUN/Cr ratio was $\geq 19.41$ after adjustment for age, sex, and ethnicity (log-rank test $p<0.001)$. The BUN/Cr ratio was used to distinguish between different survival statuses. It had good discrimination.

\section{The BUN/Cr ratio as a Predictor of In-hospital Mortality}

We constructed three different models to analyze the independent effects of the BUN/Cr ratio on the inhospital mortality of critically ill patients with AMI grouped according to the BUN/Cr ratio tertiles. As shown in Table2, in model I, after adjustment for age, sex, and ethnicity, a higher BUN/Cr ratio was associated with an increased risk of in-hospital mortality compared with those in the first tertile. In model II, after adjusting for more confounding factors, the BUN/Cr ratio was found to be an independent predictor of in-hospital mortality in critically ill patients with $\mathrm{AMl}$ as well (tertile 3 vs.tertile 1 : adjusted $\mathrm{HR}, 2.14 ; 95 \% \mathrm{Cl}, 1.16-3.97$; $\mathrm{p}$ for trend<0.05). 


\section{Analyses of the nonlinear relationship between the BUN/Cr ratio and in-hospital mortality}

It is essential to analyze the nonlinear relationships among continuous variables. In this study (Fig.3), we detected a nonlinear relationship between the BUN/Cr ratio and in-hospital mortality after adjusting for age, sex, and ethnicity. Using the two-piecewise linear regression model, we calculated the inflection point as 18. The HR $(95 \% \mathrm{Cl})$ and $p$ values were $1.31(1.15,1.49)$ and $<0.0001$, respectively, on the right of the inflection point. However, on the left of the inflection point, the BUN/Cr ratio-mortality relationship was insignificant (HR = 0.99,95\% Cl: 0.91, 1.07; $\mathrm{p}=0.7299 ;$ Table3).

\section{Subgroup analyses}

The results of the subgroup analyses are presented in Table4. After adjusting for potential confounders, we found that the test for the interaction was statistically significant for history of CHF ( $p$ for interaction<0.0001) and the AMI category ( $p$ for interaction=0.0002). However, statistical significance was not observed for age, sex, BMI, history of diabetes, history of hypertension, PCI, CABG, glucose, heart rate, and LDL. We also found evidence of BUN/Cr-AMI category interactions. The effect of the BUN/Cr ratio on in-hospital mortality significantly differed among patients with different AMI categories. The BUN/Cr ratio was positively correlated with in-hospital mortality (HR $=1.25,95 \% \mathrm{Cl}$ : $[1.14,1.37])$ in patients with non-STsegment elevation myocardial infarction(non-STEMI). However, there was no significant relationship between the BUN/Cr ratio and the in-hospital mortality in patients with ST-segment elevation myocardial infarction (STEMI). Moreover, we observed that the BUN/Cr ratio was positively correlated with the inhospital mortality if the BUN/Cr ratio was $>18$.

\section{Prediction of in-hospital mortality}

The ROC curves generated using the indicated variables(BUN/Cr plus APACHE scores and APACHE scores) are plotted in Supplementary Fig. 2. The AUCs for the APACHE scores were 0.859 and 0.861 for BUN/Cr plus APACHE scores (all $p<0.001$ ).

\section{Discussion}

The results of our study showed that an elevated BUN/Cr ratio indicated an increased risk of in-hospital death in patients with AMI. Even after adjusting for other mixed factors in the multivariate models, the $\mathrm{BNU} / \mathrm{Cr}$ ratio was associated with adverse outcomes. Our results confirmed the findings of the aforementioned studies and even went a step further. We found that there was a nonlinear relationship between BUN/Cr and in-hospital mortality in patients with AMI. Upon conducting a subgroup analysis, it was found that BUN/Cr was associated with an increased risk of in-hospital death in critically ill AMI patients. The AUC of the BUN/Cr ratio plus APACHE score had a predictive value. 
AMI is a common cause of hospital admissions, readmissions, and mortality worldwide [20]. Despite the widespread use of reperfusion techniques and improvements in adjunctive medical therapies, patients with AMI still face a substantial risk of further cardiovascular events and mortality [21].

BUN was not a specific marker of renal insufficiency; therefore, predictions based on BUN or $\mathrm{Cr}$ alone might have limitations. $\mathrm{Cr}$ is affected by extra renal factors, such as muscle mass, sex, age, nutrition, and race. Although estimated GFR improves the assessment of renal function, overestimation and underestimation still exist among patients with a wide range of serum Cr levels [22]. Similarly, the serum concentrations of BUN are influenced by many factors [23]. Hence, it is not necessarily a marker of decreased glomerular filtration rate [24].Therefore, the BUN/Cr ratio has been proposed as a useful parameter for reducing the above influencing factors. The BUN/Cr ratio might be a more stable and accurate marker for evaluating the prognosis of patients with AMI than serum $\mathrm{Cr}$ or BUN individually $[9,25]$. Brisco et al. [26] also found a significant association between an elevated BUN/Cr ratio upon admission and increased mortality. An elevated BUN/Cr ratio usually indicated serious medical conditions and poor prognosis in patients with acute kidney injury and acute heart failure (AHF) [7,27]. Qian et al. [1] reported that AHF combined with elevated BUN/Cr ratio was associated with an increased risk of mortality in patients with AMI. This finding suggested that the BNU/Cr ratio had a predictive value for prognosis in patients with AMI complicated with AHF. Takaya et al. $[23,28]$ found that a BUN/Cr ratio $\geq 22$ was associated with poor survival prognosis in patients with AHF. In addition, Murata et al. [29] indicated that the BUN/Cr ratio played a vital role in the treatment and clinical follow-up of patients with AMI since there was a strong correlation between a high $\mathrm{BUN} / \mathrm{Cr}$ ratio and long-term mortality in patients with AMI. In our study, we found that the BUN/Cr ratio had a predictive value for the prognosis of patients with AMI. However, Nunez [30] demonstrated that in patients with AMI without AHF, there was no correlation between the BUN/Cr ratio and prognosis. We considered that this might be related to some factors that might have affected the baseline BUN/Cr, such as high protein diet and hepatic insufficiency. In our study, we investigated patients with AMI who were enrolled in a multicenter registry. Younger patients and patients with severely impaired renal function were excluded. These patients were treated with standard treatments, including $\mathrm{PCl}$ and medical therapy. Therefore, these patients were part of a more representative AMI population than those in prior studies.

There is a close bidirectional relationship between the heart and kidney. This relationship is reflected in the cardiorenal syndrome(CRS). There are five types of the cardiorenal syndrome (CRS). CRS type 1 is characterized by the development of acute kidney injury and dysfunction in patients with acute cardiac illness [31]. Cardiac function in patients with AMI has a different degree of reduction in the short term [3233].Thus, the BUN/Cr ratio has a greater guiding value in the clinical treatment of AMI patients[1]. It is currently widely believed that activation of the RAAS and SNS systems is associated with adverse prognosis [34]. For patients with a complicated AMI complicated, a higher BUN/Cr ratio reflected a more active neurohormonal system. The pathophysiology of renal dysfunction in AMI is complex, multifactorial, and not completely understood. Nonetheless, an imbalance between abnormal hemodynamic, neurohormonal activation inflammatory responses, intrinsic tubular damage, and heterogeneous response to therapeutic interventions have been proposed as the most common pathogenic pathways [24]. 
This study has several strengths. This study was the first to investigate the relationship between the BUN/Cr ratio and in-hospital mortality in patients with AMI based on a large and diverse population from a public database (the eICU-CRD database) [13], which increased the significance of our research results. In addition, after adjusting for several confounding factors, multiple Cox regression analyses were performed, and the relationship between the BUN/Cr ratio and in-hospital mortality was still observed, indicating the good stability of our results. Since the BUN/Cr ratio was the basic index of clinical blood routine, the parameters were simple to collect. Our research results can be used to support other death indexes and improve prognosis prediction accuracy for AMI patients. Therefore, the BUN/Cr ratio is recommended for use in predicting the in-hospital mortality of AMI because it is cost-effective and easy to apply.

Although our study was based on a large multicenter critical care database, it still has some limitations. First, this was a retrospective study derived from an observational study, which could not definitively establish causality. Second, as this was an observational study, although a multifactor analysis was performed, other confounding factors might still exist; third, the data were from the United States, and thus the results may not apply fully to ICUs elsewhere with different practices or resources. Fourth, only data from a single BUN/Cr test were available at admission; no repeated testing was performed during the longterm follow-up, which may have resulted in biases in the study results. Finally, data on patient use of intra aortic balloon pump (IABP) and left ventricular assist device (LAVD) were not available in this study.

\section{Conclusions}

Our findings showed that a higher BUN/Cr ratio was associated with an increased risk of in-hospital mortality in patients with AMI. These results supported a revision of how we predicted the prognosis of patients with AMI. Most importantly, these findings suggested that the BUN/Cr ratio might be a useful indicator for risk stratification in patients with critically ill AMI. Further prospective studies are required to confirm these findings.

\section{Abbreviations}

AMI, Acute myocardial infarction (AMI); BUN, blood urea nitrogen; $\mathrm{Cr}$, creatinine; elCU-CRD, theeICU Collaborative Research Database; BMI, body mass index; eGFR, estimated glomerular filtration rate; RDW, red blood cell distribution width; ALT, alanine transaminase; AST, aspartatetransaminase; TC, total cholesterol; TG, triglyceride; HDL, high density lipoprotein; LDL, low density lipoprotein; INR: international normal ratio; HR: heart rate; SBP, systolic blood pressure; $\mathrm{DBP}$, diastolic blood pressure; $\mathrm{PCl}$, percutaneous coronary intervention; $\mathrm{CABG}$, coronary artery bypass grafting; $\mathrm{CHF}$, congestive heart failure; $\mathrm{AMI}$, acute myocardial infarction; STEMI, ST-segment elevation myocardial infarction; Non-STEMI, non-ST-segment elevation myocardial infarction; AHF, acute heart failure.

\section{Declarations}

\section{Acknowledgments}


We would like to express our gratitude to all the investigators and subjects who participated in this project. We would also like to thank Editage (www.editage.cn) for English language editing.

\section{Authors' contributions}

SH and XD conceived the study. SH, NG and YL carried out the research. XD, ZZ and QZ analysed the data. $\mathrm{SH}, \mathrm{LL}$ and $\mathrm{LG}$ wrote the paper. All authors read and approved the final manuscript.

\section{Funding}

This study was supported by the Technology Research and Development Fund Project of the Changde Science and Technology Bureau (Grant number: 2019S191).

\section{Data availability}

The data analyzed during the present study are currently stored in the elCU database (eicucrd.mit.edu). After completing the required training course(the Collaborative Institutional Training Initiative) and after requesting access to the eICU Collaborative Research Database, researchers can seek to use the database.

\section{Ethics approval and consent to participate}

The establishment of this database was approved by the Massachusetts Institute of Technology (Cambridge, MA), and consent was obtained for the original data collection. The database is released under the Health Insurance Portability and Accountability Act (HIPAA) safe harbor provision. The re-identification risk was certified as meeting safe harbor standards by Privacert (Cambridge, MA) (HIPAA Certification no. 1031219-2).Since all protected health information was de-identified, the requirement for individual patient consent was waived. The Ethics Committee of the First People's Hospital of Changde(No.2021-244-01) approved this retrospective data-only study. In addition, they waived the need for informed consent due to the retrospective nature of the study.

\section{Consent for publication}

Not Applicable

\section{Competing interests}

The authors reported no conflicts of interest in this work.

\section{References}

1. Qian $\mathrm{H}$, Tang C, Yan G.Predictive value of blood urea nitrogen/creatinine ratio in the long-term prognosis of patients with acute myocardial infarction complicated with acute heart failure.Medicine(Baltimore) 2019,98(11):e14845.

2. Ok F, Erdogan O, Durmus E, Carkci S, Canik A. Predictive values of blood ureanitrogen/creatinine ratio and other routine blood parameters on disease severity and survival of COVID-19 patients.J Med Virol 
2020,93(2):786-793.

3. Liu J, Sun LL, Wang J, Ji G.Blood urea nitrogen in the prediction of in-hospital mortality of patients with acute aortic dissection. Cardiol J 2018,25(3):371-376.

4. Küçükceran K, Ayrancı MK, Girişgin AS. The role of the BUN/albumin ratio in predicting mortality in COVID-19 patients in the emergency department. Am J Emerg Med 2021,48:33-37.

5. Horiuchi Y, Aoki J, Tanabe K, Nakao K, Ozaki Y, Kimura K, AkoJ, Yasuda S, Noguchi T, SuwaS, Fujimoto K, Nakama Y, Morita T, Shimizu W, Saito Y, Hirohata A, Morita Y, Inoue T, Okamura A, Uematsu M, Hirata K, Shibata Y, Nakai M, Nishimura K, Miyamoto Y, Ishihara M, J-MINUET investigators. A High level of blood urea nitrogen is a significant predictor for in-hospital mortality in patients with acute myocardial infarction. Int Heart J 2018,59(2):263-271.

6. Granger CB, Goldberg RJ, Dabbous O, Pieper KS, Eagle KA, Cannon CP, Van de Werf F, Avezum A, Goodman SG, Flather MD, Fox K A A Fox, Global Registry of Acute Coronary Events Investigators.Predictors of hospital mortality in the global registry of acute coronary events. Arch Intern Med 2003,163(19):2345-2353.

7. Matsue Y, van der Meer P, Damman K,Metra M, O'Connor CM, PonikowskiP, Teerlink JR, Cotter G, Davison B, Cleland JG, GivertzMM, Bloomfield DM, Dittrich HC, Gansevoort RT, Bakker SJ, van der Harst P, Hillege HL, van VeldhuisenDJ, Voors AA.Blood urea nitrogen-to-creatinine ratio in the general population and in patients with acute heart failure. Heart 2017,103(6):407-413.

8. Sood MM, Saeed M, Lim V,Cordova F, Komenda P, Malik A, RigattoC, Shafer LA, Tangri N, Tappia PS, Zieroth S.The urea-to-creatinine ratio is predictive of worsening kidney function in ambulatory heart failure patients. J Card Fail 2015,21(5):412-418.

9. Zhu X, Cheang I, Liao S, Wang K, Yao W, Yin T, Lu X, Zhou Y, Zhang H, Li X. Blood Urea Nitrogen to Creatinine Ratio and Long-Term Mortality in Patients with Acute Heart Failure: A Prospective Cohort Study and Meta-Analysis. Cardiorenal Med 2020,10(6):415-428.

10. Tanaka S, Ninomiya T, Taniguchi M,Tokumoto M, MasutaniK, OoboshiH, KitazonoT, Tsuruya K. Impact of blood urea nitrogen to creatinine ratio on mortality and morbidity in hemodialysis patients: the Qcohort study. Sci Rep 2017,7(1):14901.

11. SchrockJW, Glasenapp M, Drogell K. Elevated blood urea nitrogen/creatinine ratio is associated with poor outcome in patients with ischemic stroke. Clin Neurol Neurosurg 2012,114(7):881-884.

12. Brisco MA, Coca SG, Chen J, Owens AT, McCauley BD, Kimmel SE, Testani JM. Blood urea nitrogen/creatinine ratio identifies a high-risk but potentially reversible form of renal dysfunction in patients with decompensated heart failure. Circ Heart Fail 2013,6(2):233-239.

13. Pollard TJ, Johnson AEW, Raffa JD, Celi LA, Mark RG, Badawi O.The elCU Collaborative Research Database, a freely available multi-center database for critical care research. Sci Data 2018,5:180178.

14. Su D, Li J, Ren J,Gao Y, Li R, JinX, Zhang J, Wang G. The relationship between serum lactate dehydrogenase level and mortality in critically ill patients. Biomark Med 2021,15(8):551-559.

15. Thygesen K, Alpert JS, Jaffe AS, Chaitman BR, Bax JJ, Morrow DA, White HD, and The Executive Group on behalf of the Joint European Society of Cardiology (ESC)/American College of Cardiology (ACC)/American Heart Association (AHA)/World Heart Federation (WHF) Task Force for the Universal 
Definition of Myocardial Infarction. Fourth Universal Definition of Myocardial Infarction.Circulation 2018,138(20):e618-e651.

16. Schiele F, Aktaa S, Rossello X, Ahrens I, Claeys MJ, Collet J, Fox KAA, Gale CP, Huber K, lakobishvili Z, Keys A, Lambrinou E, Leonardi S, Lettino M, Masoudi FA, Price S, Quinn T, Swahn E, Thiele H, Timmis A, Tubaro M, VrintsC JM, Walker D, Bueno H, ESC Scientific Document Group, Halvorsen S, Jernberg T, Jortveit J, Blöndal M, Ibanez B, Hassager C.Update of the quality indicators for acute myocardial infarction: a position paper of the Association for Acute Cardiovascular Care: the study group for quality indicators from the ACVC and the NSTE-ACS guideline group. Eur Heart J Acute Cardiovasc Care 2020,10(2):224-233.

17. Kernan WN, Viscoli CM, Brass LM, Broderick JP, Brott T, Feldmann E, Morgenstern LB, Wilterdink JL, Horwitz RI.Phenylpropanolamine and the risk of hemorrhagic stroke. N Engl J Med 2000,343:18261832.

18. Liu S, Wang X, Lu Y, Hao L,Xin W.The effects of intraoperative cryoprecipitate transfusion on acute renal failure following orthotropic liver transplantation. Hepatol Int 2013,7(3):901-909.

19. Deng L, Qiu S, Wang C, Bian H, Wang L, Li Y, Wu B, Liu M. Effects of the blood urea nitrogen to creatinine ratio on hamorrhagic transformation in AIS patients with diabetes mellitus. BMC Neurol 2019,19(1):63.

20. Bhardwaj V, Spaulding EM, Marvel FA, LaFave S, Yu J, Mota D, LorigianoT, Huynh P, Shan R, YesantharaoPS, Lee MA, Yang WE, Demo R, Ding J, Wang J, Xun H, Shah L, Weng D, WongvibulsinS, Carter J, Sheidy J, McLin R, Flowers J, Majmudar M, Elgin E, Vilarino V, LumelskyD, Leung C, Allen JK, Martin SS, Padula WV.Affiliations expand Cost-effectiveness of a Digital Health Intervention for Acute Myocardial Infarction Recovery. Med Care 2021,59(11):1023-1030.

21. Piironen $\mathrm{M}$, Ukkola $\mathrm{O}$, Huikuri $\mathrm{H}$. Trends in long-term prognosis after acute coronary syndrome. Eur $\mathrm{J}$ PrevCardiol 2017,24(3):274-280.

22. Kimura K, Morita H, Daimon M, Kawata T, Nakao T, Hirokawa M, Kitao R, Watanabe D, Komori T, Nagata T, TakedaS, Komaki H, Segawa K, Nakajima T, Takenaka K, Komuro I.Utility of cystatin C for estimating glomerular filtration rate in patients with muscular dystrophy. Int Heart J 2016,57(3): 386-388.

23. Han D, Zhang L, Zheng S, Xu F, Li C, Yang R, Ma W, Yin H, Lyu J.Prognostic Value of Blood Urea Nitrogen/Creatinine Ratio for Septic Shock: An Analysis of the MIMIC-III Clinical Database. Biomed Res Int 2021:5595042.

24. Núñez J, Miñana G, Santas E, Bertomeu-González V.Cardiorenal syndrome in acute heart failure: revisiting paradigms.Rev EspCardiol (Engl Ed) 2015,68(5):426-435.

25. Otto CM. Heartbeat:Blood urea nitrogen to creatinine ratio predicts outcome in acute heart failure. Heart 2017,103(6):399-401.

26. Brisco MA, Zile MR, Ter Maaten JM, Hanberg JS, Wilson FP, Parikh C, Testani JM. The risk of death associated with proteinuria in heart failure is restricted to patients with an elevated blood urea nitrogen to creatinine ratio. Int J Cardiol 2016,215:521-526.

27. Uchino S, Bellomo R, Goldsmith D.The meaning of the blood urea nitrogen/creatinine ratio in acute kidney injury. Clin Kidney J 2015,5(2):187-91.

Page $11 / 22$ 
28. Parrinello G,Torres D,Testani JM, Almasio JM, Luigi P, Michele B. Blood urea nitrogen to creatinine ratio is associated with congestion and mortality in heart failure patients with renal dysfunction.Intern Emerg Med 2015,10(8):965-972.

29. Murata A, Kasai T, Matsue Y, Matsumoto H, YatsuS, Kato T, Suda S, Hiki M, Takagi A, Daida H.Relationship between blood urea Nitrogen-to-creatinine ratio at hospital admission and long-term mortality in patients with acute decompensated heart failure. Heart Vessels 2018,33(8):877-885.

30. Nuñez J.Blood urea nitrogen to creatinine ratio in acute heart failure: an old concept brought to reality? Heart 2017,103(6):402-403.

31. Schefold JC, Lainscak M, HodoscekLM, Blöchlinger S, Doehner W, von HaehlingS. Single baseline serum creatinine measurements predict mortality in critically ill patients hospitalized for acute heart failure. ESC Heart Fail 2015,2(4):122-128.

32. Ibanez B, James S, Agewall S, Antunes MJ, Bucciarelli-Ducci C, Bueno H, Caforio ALP, Crea F, Goudevenos JA, Halvorsen S, Hindricks G, Kastrati A, Lenzen MJ, Prescott E, Roffi M, Valgimigli M, VarenhorstC, Vranckx P, Widimský P, ESC Scientific Document Group.2017 ESC guidelines for the management of acute myocardial infarction in patients presenting with ST-segment elevation: the task force for the management of acute myocardial infarction in patients presenting with ST-segment elevation of the European Society of Cardiology (ESC). Eur Heart J 2018,39(2):119-177.

33. Chew DP, Scott IA, Cullen L, French JK, Briffa TG, Tideman PA, WoodruffeS, Kerr A, Branagan M, Aylward PEG. NHFA/CSANZ ACS Guideline 2016 Executive Working Group: National Heart Foundation of Australia \& Cardiac Society of Australia and New Zealand: Australian clinical guidelines for the management of acute coronary syndromes 2016. Heart Lung Circ 2016,25(9):895-951.

34. Borghi C, Omboni S, Reggiardo G, Bacchelli S, Esposti DD, AmbrosioniE, SMILE Working Project.Effects of the concomitant administration of xanthine oxidase inhibitors with zofenopril or other ACE-inhibitors in post-myocardial infarction patients: a meta-analysis of individual data of four randomized, doubleblind, prospective studies.BMC Cardiovasc Disord 2018,18(1):112.

\section{Tables}

Table 1 Participants' Baseline Characteristics 


\begin{tabular}{|c|c|c|c|c|c|}
\hline \multirow[t]{2}{*}{ BUN/Cr group } & \multirow[t]{2}{*}{ All } & \multicolumn{3}{|c|}{ Tertiles of $\mathrm{BNU} / \mathrm{Cr}$} & \multirow{2}{*}{$\begin{array}{l}\text { P- } \\
\text { value }\end{array}$} \\
\hline & & $\mathrm{T} 1$ & $\mathrm{~T} 2$ & T3 & \\
\hline $\mathrm{N}$ & 3,831 & 1,271 & 1,274 & 1,286 & \\
\hline Age,years & $\begin{array}{l}65.00(55.00- \\
75.0)\end{array}$ & $\begin{array}{l}60.00(51.00- \\
69.00)\end{array}$ & $\begin{array}{l}65.00(56.00- \\
73.00)\end{array}$ & $\begin{array}{l}71.00(61.00- \\
79.00)\end{array}$ & $<0.001$ \\
\hline Gender,n(\%) & & & & & $<0.001$ \\
\hline Female & $1142(29.81 \%)$ & 269 (33.85\%) & $329(32.45 \%)$ & $544(40.72 \%)$ & \\
\hline male & $2689(70.19 \%)$ & 1002 (66.15\%) & 945 (67.55\%) & $742(59.28 \%)$ & \\
\hline Ethnicity,n(\%) & & & & & $<0.001$ \\
\hline Caucasian & $2976(78.88 \%)$ & 911 (72.94\%) & 1012(80.64\%) & 1053(82.98\%) & \\
\hline Non-Caucasian & 797 (21.12\%) & 338 (27.06\%) & $243(19.36 \%)$ & $216(17.02 \%)$ & \\
\hline $\mathrm{BMI}, \mathrm{kg} / \mathrm{m}^{2}$ & $\begin{array}{l}28.26(24.69- \\
32.86)\end{array}$ & $\begin{array}{l}28.42(24.98- \\
32.69)\end{array}$ & $\begin{array}{l}28.59(25.10- \\
33.35)\end{array}$ & $\begin{array}{l}27.82(24.07- \\
32.52)\end{array}$ & $<0.001$ \\
\hline $\begin{array}{l}\text { Length of stay } \\
\text { hospital,days }\end{array}$ & $\begin{array}{l}3.85(2.28- \\
7.82)\end{array}$ & $\begin{array}{l}3.11(2.10- \\
6.49)\end{array}$ & $\begin{array}{l}3.46(2.19- \\
7.33)\end{array}$ & $\begin{array}{l}5.25(2.93- \\
9.23)\end{array}$ & $<0.001$ \\
\hline $\mathrm{BUN} / \mathrm{Cr}$ & $\begin{array}{l}16.96(13.59- \\
21.67)\end{array}$ & $\begin{array}{l}12.20(10.38- \\
13.57)\end{array}$ & $\begin{array}{l}16.90(15.72- \\
18.28)\end{array}$ & $\begin{array}{l}24.48(21.63- \\
28.77)\end{array}$ & $<0.001$ \\
\hline $\begin{array}{l}\text { eGFR,ml/min/per } \\
1.73 \mathrm{~m}^{2}\end{array}$ & $\begin{array}{l}86.08(73.85- \\
103.11)\end{array}$ & $\begin{array}{l}83.67(72.94- \\
99.68)\end{array}$ & $\begin{array}{l}85.80(74.03- \\
102.21)\end{array}$ & $\begin{array}{l}89.58(74.57- \\
110.42)\end{array}$ & $<0.001$ \\
\hline WBC, ${ }^{\star} 10^{\wedge} 9$ & $\begin{array}{l}10.80(8.30- \\
13.90)\end{array}$ & $\begin{array}{l}10.50(8.10- \\
13.30)\end{array}$ & $\begin{array}{l}10.73(8.20- \\
13.60)\end{array}$ & $\begin{array}{l}11.10(8.50- \\
15.10)\end{array}$ & $<0.001$ \\
\hline $\mathrm{RBC},{ }^{\star} 10^{\wedge} 9$ & $\begin{array}{l}4.14(3.61- \\
4.60)\end{array}$ & $\begin{array}{l}4.29(3.78- \\
4.72)\end{array}$ & $\begin{array}{l}4.24(3.71- \\
4.62)\end{array}$ & $\begin{array}{l}3.92(3.43- \\
4.39)\end{array}$ & $<0.001$ \\
\hline RDW,\% & $\begin{array}{l}13.90(13.30- \\
15.00)\end{array}$ & $\begin{array}{l}13.70(13.10- \\
14.70)\end{array}$ & $\begin{array}{l}13.80(13.20- \\
14.80)\end{array}$ & $\begin{array}{l}14.40(13.50- \\
15.50)\end{array}$ & $<0.001$ \\
\hline Platelets, ${ }^{\star} 10^{\wedge} 9$ & $\begin{array}{l}203.00(163.00- \\
250.00)\end{array}$ & $\begin{array}{l}205.00(168.00- \\
251.00)\end{array}$ & $\begin{array}{l}203.00 \\
(165.00- \\
248.00)\end{array}$ & $\begin{array}{l}200.00 \\
(156.00- \\
250.00)\end{array}$ & 0.008 \\
\hline AST,U/L & $\begin{array}{l}\text { 67.00(33.00- } \\
168.00)\end{array}$ & $\begin{array}{l}70.00(33.00- \\
161.25)\end{array}$ & $\begin{array}{l}\text { 64.00(31.00- } \\
170.00)\end{array}$ & $\begin{array}{l}64.00(33.00- \\
173.25)\end{array}$ & 0.749 \\
\hline ALT,U/L & $\begin{array}{l}36.00(22.00- \\
67.00)\end{array}$ & $\begin{array}{l}34.50(22.75- \\
61.00)\end{array}$ & $\begin{array}{l}36.00(23.00- \\
65.00)\end{array}$ & $\begin{array}{l}36.00(22.00- \\
73.00)\end{array}$ & 0.509 \\
\hline $\mathrm{TC}, \mathrm{mmol} / \mathrm{L}$ & $\begin{array}{l}158.00(130.00- \\
188.00)\end{array}$ & $\begin{array}{l}163.00(136.00- \\
195.00)\end{array}$ & $\begin{array}{l}158.00(131.00- \\
186.00)\end{array}$ & $\begin{array}{l}148.00(120.00- \\
181.00)\end{array}$ & $<0.001$ \\
\hline TG,mmol/L & $\begin{array}{l}117.00(83.00- \\
171.25)\end{array}$ & $\begin{array}{l}122.00(89.00- \\
177.00)\end{array}$ & $\begin{array}{l}115.00(83.25- \\
172.00)\end{array}$ & $\begin{array}{l}111.00(77.00- \\
163.00)\end{array}$ & $<0.001$ \\
\hline $\mathrm{HDL}, \mathrm{mmol} / \mathrm{L}$ & $38.00(31.00-$ & $38.00(31.00-$ & $37.00(31.00-$ & $39.00(31.00-$ & 0.021 \\
\hline
\end{tabular}




\begin{tabular}{|c|c|c|c|c|c|}
\hline & $46.00)$ & $46.00)$ & $46.00)$ & $48.00)$ & \\
\hline $\mathrm{LDL}, \mathrm{mmol} / \mathrm{L}$ & $\begin{array}{l}90.00(66.00- \\
119.00)\end{array}$ & $\begin{array}{l}95.00(70.00- \\
124.50)\end{array}$ & $\begin{array}{l}90.50(68.00- \\
117.00)\end{array}$ & $\begin{array}{l}82.00(59.00- \\
111.00)\end{array}$ & $<0.001$ \\
\hline Potassium,mmol/L & $\begin{array}{l}4.10(3.80- \\
4.40)\end{array}$ & $\begin{array}{l}4.00(3.70- \\
4.30)\end{array}$ & $\begin{array}{l}4.00(3.80- \\
4.30)\end{array}$ & $\begin{array}{l}4.10(3.80- \\
4.50)\end{array}$ & $<0.001$ \\
\hline Sodium,mmol/L & $\begin{array}{l}138.00(135.00- \\
140.00)\end{array}$ & $\begin{array}{l}138.00(135.00- \\
140.00)\end{array}$ & $\begin{array}{l}138.00(136.00- \\
140.00)\end{array}$ & $\begin{array}{l}138.00(135.00- \\
140.00)\end{array}$ & 0.003 \\
\hline INR & $\begin{array}{l}1.20(1.09- \\
1.40)\end{array}$ & $\begin{array}{l}1.20(1.10- \\
1.40)\end{array}$ & $\begin{array}{l}1.20(1.08- \\
1.40)\end{array}$ & $\begin{array}{l}1.20(1.07- \\
1.40)\end{array}$ & 0.413 \\
\hline HR,beats/minutes & $\begin{array}{l}81.00(69.00- \\
94.00)\end{array}$ & $\begin{array}{l}81.00(69.00- \\
94.00)\end{array}$ & $\begin{array}{l}81.00(70.00- \\
94.00)\end{array}$ & $\begin{array}{l}80.00(69.00- \\
94.0)\end{array}$ & 0.851 \\
\hline SBP,mmHg & $\begin{array}{l}123.00(104.00- \\
143.00)\end{array}$ & $\begin{array}{l}123.00(104.00- \\
143.00)\end{array}$ & $\begin{array}{l}121.50 \\
(103.00- \\
143.25)\end{array}$ & $\begin{array}{l}123.00 \\
(104.00- \\
143.00)\end{array}$ & 0.908 \\
\hline $\mathrm{DBP}, \mathrm{mmHg}$ & $\begin{array}{l}62.00(51.00- \\
74.0)\end{array}$ & $\begin{array}{l}62.00(51.00- \\
73.00)\end{array}$ & $\begin{array}{l}63.00(51.00- \\
74.00)\end{array}$ & $\begin{array}{l}61.00(51.00- \\
74.00)\end{array}$ & 0.898 \\
\hline $\mathrm{PCl}, \mathrm{n}(\%)$ & & & & & 0.181 \\
\hline No & 3309 (86.62\%) & $1100(87.10 \%)$ & $1084(85.29 \%)$ & 1125(87.75\%) & \\
\hline yes & $511(13.38 \%)$ & $167(14.71 \%)$ & $187(14.71 \%)$ & $157(12.25 \%)$ & \\
\hline $\mathrm{CABG}, \mathrm{n}(\%)$ & & & & & 0.224 \\
\hline no & $3568(93.4 \%)$ & $1191(94.0 \%)$ & 1192 (93.78\%) & $1185(92.43 \%)$ & \\
\hline yes & $252(6.6 \%)$ & $76(6.0 \%)$ & $79(6.22 \%)$ & $97(7.57 \%)$ & \\
\hline $\mathrm{CHF}, \mathrm{n}(\%)$ & & & & & $<0.001$ \\
\hline no & $3584(93.82 \%)$ & 1227 (96.84\%) & $1200(94.41 \%)$ & 1157 (90.25\%) & \\
\hline yes & $236(6.18 \%)$ & $40(3.16 \%)$ & $71(5.59 \%)$ & $125(9.75 \%)$ & \\
\hline Diabetes,n(\%) & & & & & $<0.001$ \\
\hline No & $2890(75.65 \%)$ & $1041(82.16 \%)$ & $951(74.82 \%)$ & $898(70.05 \%)$ & \\
\hline yes & $930(24.35 \%)$ & $226(17.84 \%)$ & $320(25.18 \%)$ & 384 (29.95\%) & \\
\hline Hypertension,n(\%) & & & & & 0.003 \\
\hline No & 1905 (49.87\%) & $677(53.43 \%)$ & $629(49.49 \%)$ & $599(46.72 \%)$ & \\
\hline yes & 1915 (50.13\%) & $590(46.57 \%)$ & $642(50.51 \%)$ & $683(53.28 \%)$ & \\
\hline AMI category,n(\%) & & & & & $<0.001$ \\
\hline Non-STEMI & $1615(42.16 \%)$ & $484(38.08 \%)$ & $514(40.35 \%)$ & $617(47.98 \%)$ & \\
\hline STEMI & $2216(48.17 \%)$ & 787(61.92\%) & $760(59.65 \%)$ & $669(52.02 \%)$ & \\
\hline
\end{tabular}


Abbreviations: BMI,body mass index; eGFR,estimated glomerular filtration rate; RDW,red blood cell distribution width; ALT,alanine transaminase; AST,aspartate transaminase; TC,total cholesterol; TG,triglyceride; HDL,high density lipoprotein; LDL,low density lipoprotein; INR: international normal ratio; HR:heart rate; SBP,systolic blood pressure; DBP,diastolic blood pressure; PCl,percutaneous coronary intervention; $\mathrm{CABG}$,coronary artery bypass grafting; $\mathrm{CHF}$,congestive heart failure;AMl,acute myocardial infarction; STEMI,ST-segment elevation myocardial infarction; Non-STEMI,non-ST-segment elevation myocardial infarction

Table 2 The Relationship Between the BUN/Cr and in-hospital Mortality in Patients with AMI in Different Models

\begin{tabular}{|c|c|c|c|c|c|c|}
\hline Exposure & $\begin{array}{l}\text { Non-adjusted } \\
\text { HR(95\%Cl) }\end{array}$ & $P$ value & $\begin{array}{l}\text { Adjust I } \\
\text { HR(95\% } \mathrm{Cl})\end{array}$ & $\begin{array}{l}P \\
\text { value }\end{array}$ & $\begin{array}{l}\text { Adjust II } \\
\text { HR(95\% Cl) }\end{array}$ & $\begin{array}{l}P \\
\text { value }\end{array}$ \\
\hline $\mathrm{BUN} / \mathrm{Cr}$ & $1.09(1.04,1.14)$ & 0.0004 & $\begin{array}{l}1.08(1.03, \\
1.13)\end{array}$ & 0.0017 & $\begin{array}{l}1.21(1.05, \\
1.40)\end{array}$ & 0.0070 \\
\hline $\begin{array}{l}\text { BUN/Cr per SD } \\
\text { increase }\end{array}$ & $1.18(1.07,1.29)$ & 0.0004 & $\begin{array}{l}\text { 1.16 (1.06, } \\
1.27)\end{array}$ & 0.0017 & $\begin{array}{l}1.45(1.11, \\
1.89)\end{array}$ & 0.0070 \\
\hline \multicolumn{7}{|l|}{ BUN/Cr group } \\
\hline $\mathrm{T} 1$ & 1.0 & & 1.0 & & 1.0 & \\
\hline T2 & $0.99(0.77,1.27)$ & 0.9285 & $\begin{array}{l}1.00(0.77 \\
1.28)\end{array}$ & 0.9828 & $\begin{array}{l}0.83(0.39 \\
1.73)\end{array}$ & 0.6137 \\
\hline T3 & $1.51(1.21,1.88)$ & 0.0003 & $\begin{array}{l}1.45(1.16 \\
1.81)\end{array}$ & 0.0012 & $\begin{array}{l}2.14(1.16 \\
3.97)\end{array}$ & 0.0155 \\
\hline$P$ for trend & & $<0.0001$ & & 0.0004 & & 0.0198 \\
\hline
\end{tabular}

Notes: Models were derived from Cox proportional hazards regression models. Non-adjusted model adjust for: None Adjust I model adjust for: age; gender; ethnicity. Adjust II model adjust for: age; gender; ethnicity; BMI; HR*; HDL; LDL; ALT; AMI category; CABG; CHF; diabetes; hypertension; PCI.

Abbreviations: $\mathrm{HR}$, hazard ratio; $\mathrm{Cl}$, confidence interval; $\mathrm{BMI}$,body mass index; $\mathrm{HR}^{\star}$, heart rate; HDL,high density lipoprotein;LDL,low density lipoprotein; ALT,alanine transaminase; AMl,acute myocardial infarction; $\mathrm{CABG}$,coronary artery bypass grafting; $\mathrm{CHF}$,congestive heart failure; $\mathrm{PCl}$,percutaneous coronary intervention.

Table 3 Threshold effect analysis of the relationship between the BNU/Cr ratio and mortality using a twopiecewise regression model 


\begin{tabular}{|lll|}
\hline BUN/Cr ratio inflection point & $\begin{array}{l}\text { In-hospital mortality } \\
\text { HRロ95\%Cld }\end{array}$ & P value \\
\hline$<18$ & $0.99(0.91,1.07)$ & 0.7299 \\
\hline$\geq 18$ & $1.31(1.15,1.49)$ & $<0.0001$ \\
\hline P for log likelihood ratio test & & 0.003 \\
\hline
\end{tabular}

Notes: adjust for age; gender; ethnicity; BMl; HR*; HDL; LDL; ALT; AMI group; CABG; CHF; diabetes; hypertension; $\mathrm{PCl}$.

Abbreviations: $\mathrm{HR}$, hazard ratio; $\mathrm{Cl}$, confidence interval; BMI,body mass index; $\mathrm{HR}^{\star}$, heart rate; $\mathrm{HDL}$,high density lipoprotein;LDL,low density lipoprotein; ALT,alanine transaminase; AMI,acute myocardial infarction; $\mathrm{CABG}$,coronary artery bypass grafting; $\mathrm{CHF}$,congestive heart failure; $\mathrm{PCl}$,percutaneous coronary intervention.

Table 4 Effect size of the BUN/Cr ratio on in-hospital mortality in prespecified and exploratory subgroups 


\begin{tabular}{|c|c|c|c|}
\hline Characteristic & No of participants & Effect size $(95 \% \mathrm{Cl}), \mathrm{p}$ value & $P$ for interaction \\
\hline $\mathrm{BUN} / \mathrm{Cr}$ & & & 0.0012 \\
\hline$<18$ & 2163 & $1.02(0.93,1.12) 0.6817$ & \\
\hline$\geq 18$ & 1668 & $1.41(1.18,1.67) 0.0001$ & \\
\hline Gender & & & 0.5221 \\
\hline female & 1142 & $1.07(1.00,1.14) 0.0607$ & \\
\hline male & 2689 & $1.10(1.03,1.17) 0.0031$ & \\
\hline Age,years & & & 0.1371 \\
\hline$<65$ & 2174 & $1.41(1.06,1.87) 0.0183$ & \\
\hline$\geq 65$ & 1657 & $1.11(0.95,1.30) 0.2078$ & \\
\hline $\mathrm{BMI}, \mathrm{kg} / \mathrm{m}^{2}$ & & & 03221 \\
\hline$<28$ & 1795 & $1.12(1.05,1.19) 0.0005$ & \\
\hline$\geq 28$ & 1954 & $1.06(0.99,1.15) 0.0981$ & \\
\hline CHF & & & $<0.0001$ \\
\hline No & 3584 & $1.18(1.12,1.25)<0.0001$ & \\
\hline yea & 236 & $0.90(0.83,0.97) 0.0085$ & \\
\hline Diabetes & & & 0.0558 \\
\hline No & 2890 & $1.13(1.07,1.20)<0.0001$ & \\
\hline yea & 930 & $1.03(0.96,1.11) 0.4147$ & \\
\hline Hypertension & & & 0.5008 \\
\hline No & 1905 & $1.11(1.04,1.19) 0.0025$ & \\
\hline yes & 1915 & $1.08(1.01,1.15) 0.0252$ & \\
\hline CABG & & & 0.865 \\
\hline No & 3568 & $1.11(1.05,1.16)<0.0001$ & \\
\hline yes & 252 & $0.97(0.84,1.11) 0.6480$ & \\
\hline $\mathrm{PCl}$ & & & 0.7885 \\
\hline No & 3309 & $1.09(1.04,1.15) 0.0005$ & \\
\hline yes & 511 & $1.07(0.93,1.23) 0.3402$ & \\
\hline Glucose, mg/dl & & & 0.4807 \\
\hline$<128$ & 1799 & $1.07(1.00,1.15) 0.0407$ & \\
\hline
\end{tabular}




\begin{tabular}{|c|c|c|c|}
\hline$\geq 128$ & 1891 & $1.11(1.04,1.19) 0.0030$ & \\
\hline AMI category & & & 0.0002 \\
\hline STIMI & 1615 & $1.03(0.97,1.08) 0.3638$ & \\
\hline Non-STIMI & 2216 & $1.25(1.14,1.37)<0.0001$ & \\
\hline Heart rate, beats/min & & & 0.8459 \\
\hline$<80$ & 1781 & $1.09(1.02,1.17) 0.0102$ & \\
\hline$\geq 80$ & 2020 & $1.08(1.01,1.16) 0.0172$ & \\
\hline LDL, & & & 0.6106 \\
\hline$<90$ & 1161 & $1.22(1.06,1.41) 0.0071$ & \\
\hline$\geq 90$ & 1196 & $1.31(1.05,1.63) 0.0175$ & \\
\hline
\end{tabular}

Abbreviations: eGFR,estimated glomerular filtration rate;BMI,body mass index; $\mathrm{CHF}$,congestive heart failure; $\mathrm{CABG}$,coronary artery bypass grafting; $\mathrm{PCl}$,percutaneous coronary intervention; $\mathrm{AMI}$,acute myocardial infarction; STEMI,ST-segment elevation myocardial infarction; Non-STEMI,non-ST-segment elevation myocardial infarction; LDL,low density lipoprotein.

\section{Figures}




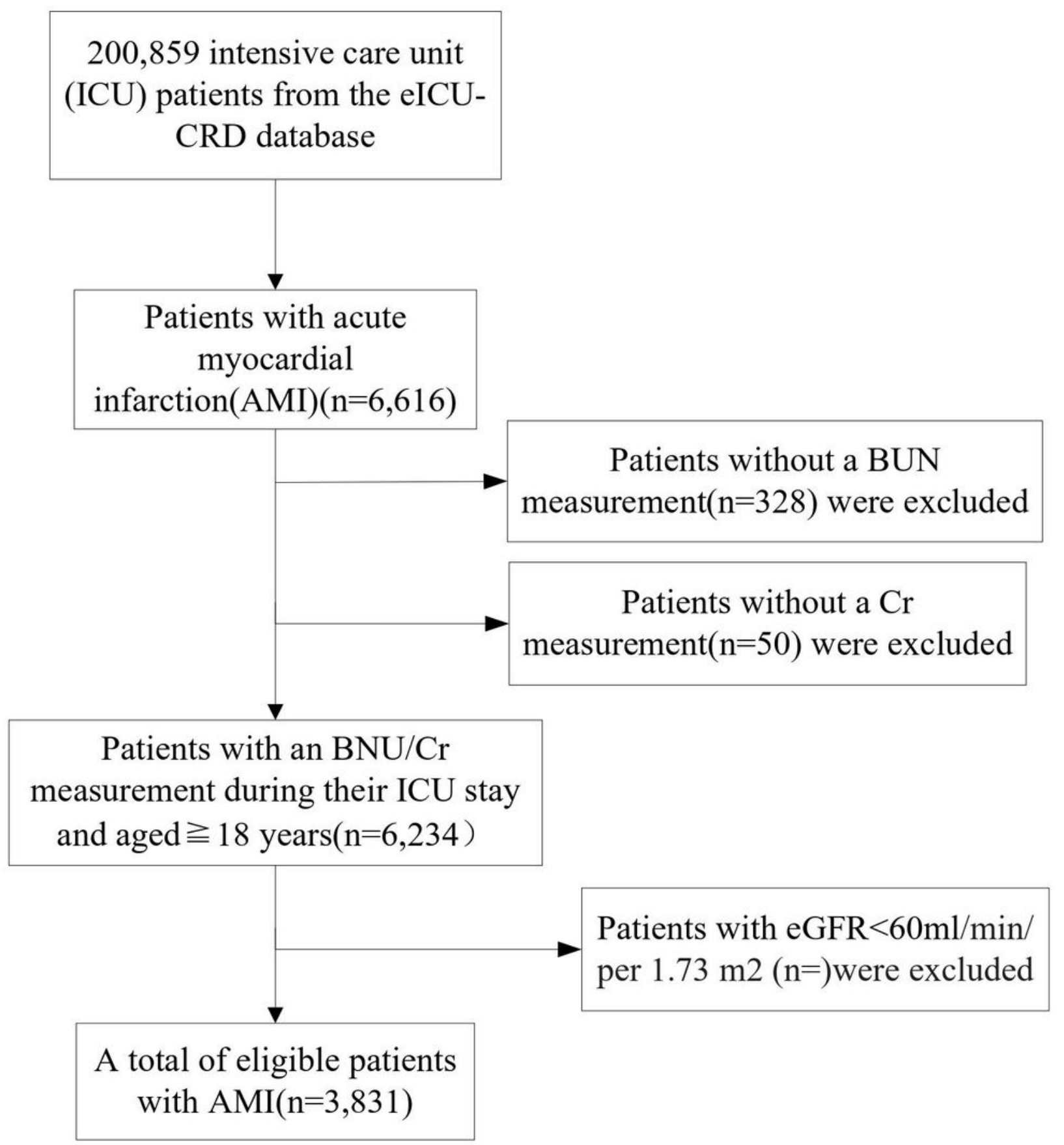

Figure 1

Flow diagram of the screening and enrollment of study patients. A total of 3,831 patients were included in the analysis. 


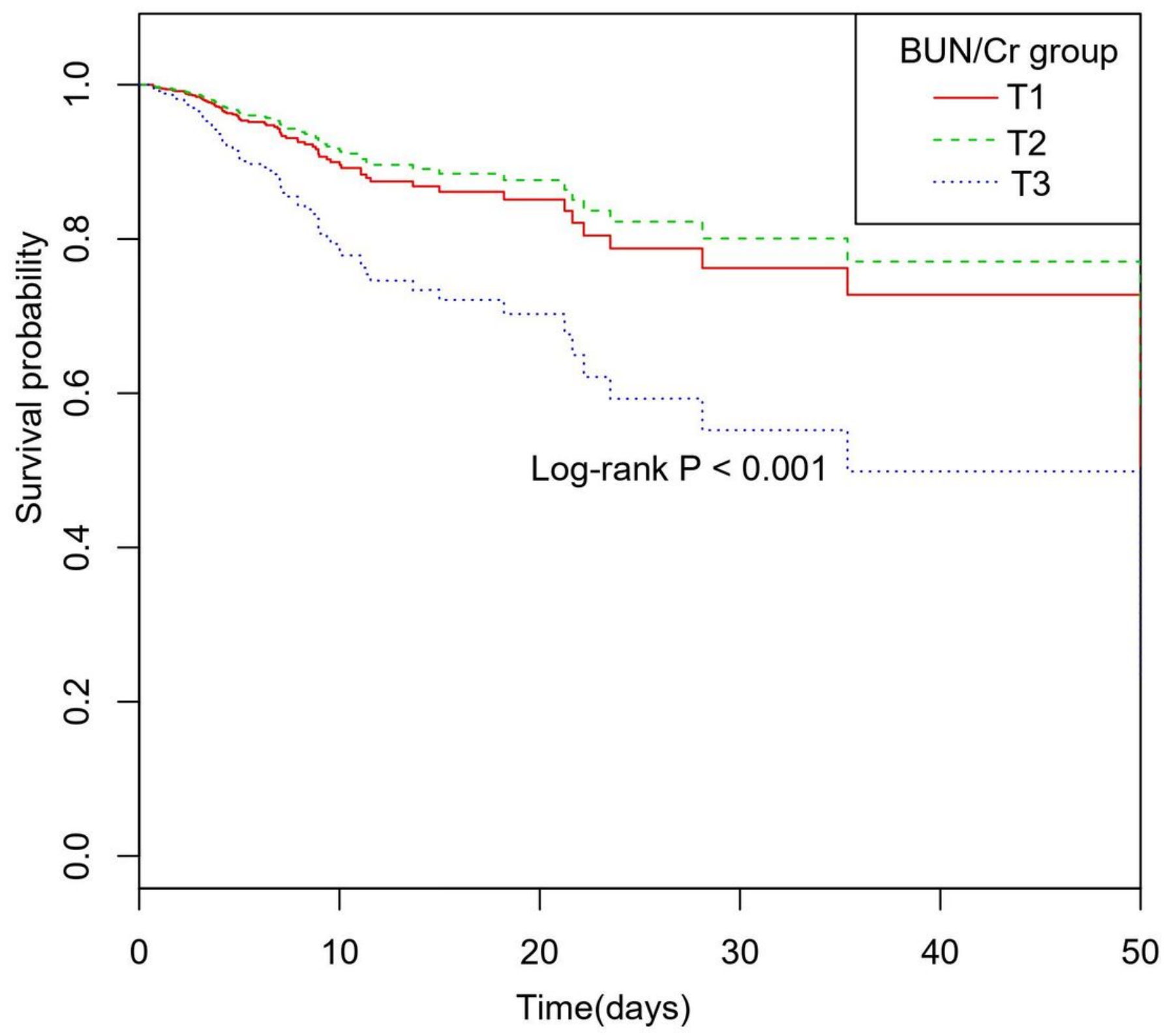

Figure 2

The Kaplan-Meier curves of the BUN/Cr ratio for predicting in-hospital mortality with AMI.A high BUN/Cr ratio was significantly associated with a higher mortality than a medium or low $B U N / C r$ ratio $(p<0.001)$. 


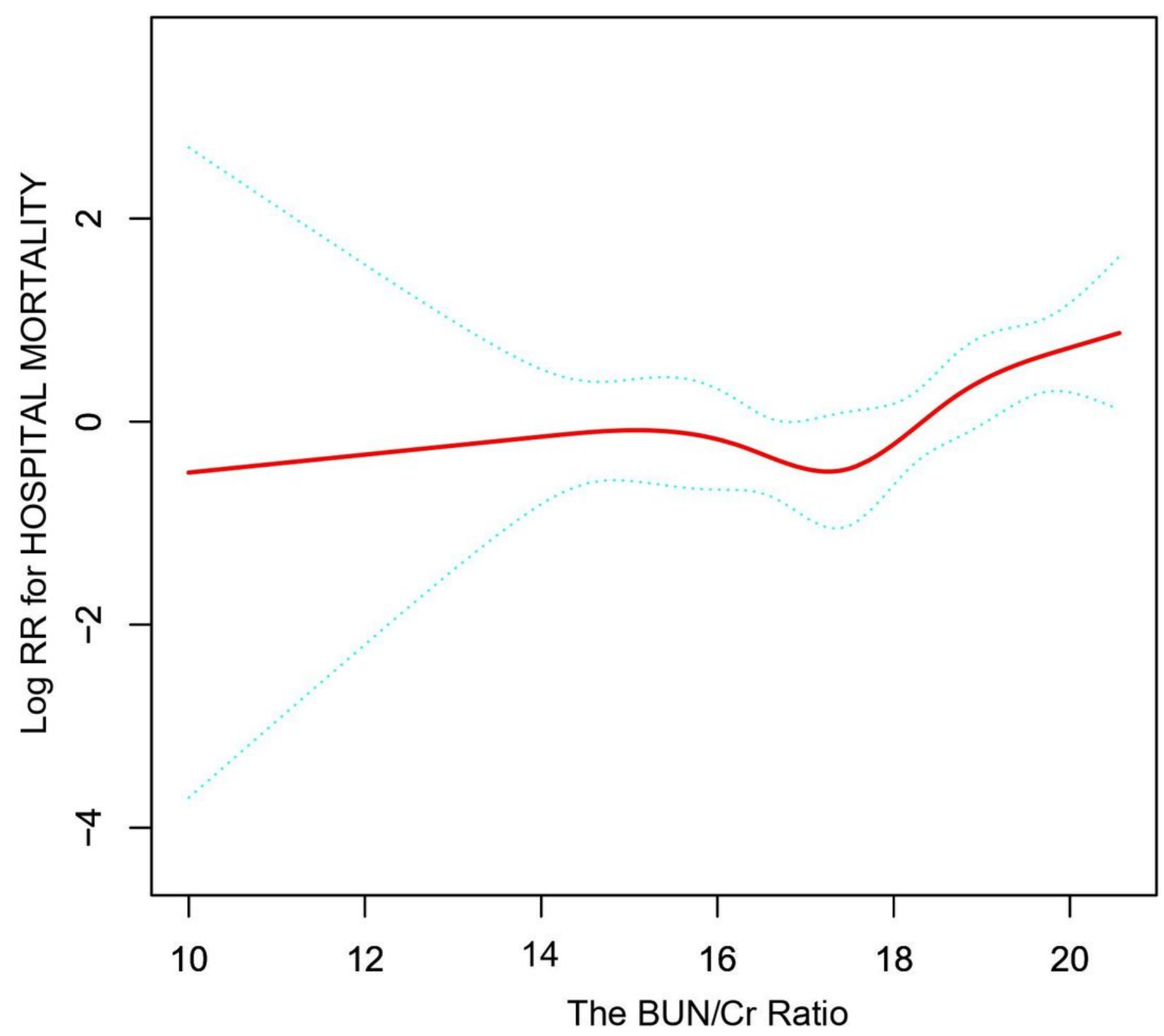

Figure 3

The non-linear relationship between BUN/Cr and in-hospital mortality.

\section{Supplementary Files}

This is a list of supplementary files associated with this preprint. Click to download.

- SupplementalFigure1.pdf 
- SupplementalFigure2.pdf

Page 22/22 